\title{
Effective Groupwork Strategies: Faculty and Students' Perspectives
}

\author{
Ali R. Rezaei ${ }^{1}$ \\ ${ }^{1}$ College of Education, California State University, Long Beach, USA \\ Correspondence: Ali R. Rezaei, College of Education, California State University, Long Beach, 1250 Bellflower, \\ Blvd, Long Beach, CA, 90840, USA.
}

Received: October 18, 2017

Accepted: March 15, 2018 Online Published: May 23, 2018

doi:10.5539/jel.v7n5p1

URL: https://doi.org/10.5539/jel.v7n5p1

\begin{abstract}
The goal of this research study was to find what makes groupwork to be successful. We asked faculty why they give groupwork assignments to their students and what their opinions about the best practices in creating effective groupwork environment for their students are. It was also intended to compare instructors' opinions with research findings to find out how much their groupwork strategies match research findings in this area. Likewise, we asked students about features of successful groupwork to see if faculty and students' viewpoints on features of successful groupwork were similar. The results reveal the most prevalent groupwork strategies practiced by faculty and the favorite ones among students. Results show faculty and students' attitudes towards groupwork are very similar, however, many faculty do not follow the guidelines suggested in earlier studies to improve the effectiveness of groupwork assignments.
\end{abstract}

Keywords: collaborative learning, interactive learning, group work, group discussion

\section{Introduction}

Many teachers are using groupwork as a teaching strategy in their courses. Yet a group of instructors refuse to assign groupwork to their students. Both groups need to learn more about effective groupwork strategies. There are many research studies supporting the idea that collaborative methods have a positive effect on student achievement in almost any discipline (Bennett, 2015; Katz \& Rezaei, 1999; Rezaei, 2015). However, the results of research on the effectiveness of groupwork is not always positive and indeed some researchers have argued that groupwork in class may not be useful at all (Qamar, Ahmad, \& Niaz, 2015; Brown \& Mcllroy, 2011).

\subsection{Background Research}

The most common teaching strategy used in classrooms has been lectures (Lammers \& Murphy 2002). However, this strategy usually lacks many of the components of active learning, such as critical thinking, self-pacing, and the encouragement of dialogue and group discussion (Fredrick \& Hummel 2004). Recently, higher education institutions are paying more attention to the development of students' communicative abilities and critical thinking. Collaborative learning is a key teaching strategy to use to develop these skills. Collaborative learning or groupwork is an instructional approach in which students work together in small or large groups to accomplish a common learning goal or a well-defined learning task (Rezaei, 2017).

Groupwork is beneficial for both students and instructors. For students, groupwork motivates them, provides a peer instruction opportunity, gives them a chance to look at the problem from multiple perspectives, and helps them to become more creative. For teachers, groupwork is an opportunity to give students more complex and authentic assignments. Collaborative learning procedures have also been shown to enhance student satisfaction with the learning and classroom experience (Groccia \& Miller, 1996). Numerous research studies have demonstrated that small-group learning creates situations in which schoolwork is perceived not as a task or chore but as an opportunity to interact on issues of personal importance (Ahern \& Durrington, 1995). The importance of collaborative learning is rooted in its potential for meaningful learning and social interaction. Various theorists, from Vygotsky (1986), to the situated learning theorists such as Lave and Wenger (1991), to the current social constructive theorists (Jong, Lai, Hsia \& Lin, 2013), have stressed the importance of social interaction in learning. These theorists propose that learning occurs in a social or inter-psychological context prior to its becoming internalized or individualized within an intra-psychological category (Vygotsky, 1986).

Recently, some authors have questioned whether educators are using groupwork just because it is popular or if there is hard evidence to prove its effectiveness (Brown \& McIlroy, 2011). Indeed, there are some negative 
reports, most of the negative reports are coming from the areas of physical or medical sciences where students work together on a well-defined project and have specific goals to reach. For example, Qamar, Ahmad, \& Niaz (2015) reported that "medical students' discussion intervention" showed poor results in terms of their mean scores in their final professional exam, their pass rates, and in terms of their perceptions of the course. These authors also report the results of other studies, which have revealed students' negative perspectives regarding the worth of "problem oriented interactive sessions." In a study about course groupwork in China, students reported: uncertainty about the accuracy of the knowledge acquired, time wasted during the session, inadequate focus in teaching, and heavy workload for the students (Huang, 2005). In a more recent study, Brown and Mcllroy (2011) reviewed several articles on students' perspectives about groupwork and concluded that rather than learning to value group collaboration, usually, students learned to hate it. The question is why these students were not happy about their groupwork and what instructors could have done to change the situation. As Chapman (2005) stressed, "working and discussing with others per se will not necessarily result in higher learning" (p. 289). Asking a group of students to decide if they preferred individual or groupwork, Brown and McIlroy (2011) found that $68.9 \%$ preferred to do individual projects, $26.4 \%$ preferred group assignments and $4.6 \%$ had no preference. They reported that students' comments mirrored those issues raised in the literature review regarding time management, personal control, and concern over the quality of the outcome (Cartney \& Rouse, 2006).

In summary, while there are many studies which support groupwork and most of them have reported positive results, the above examples indicate that groupwork is not always successful and that designing a collaborative environment is not always easy. A closer look at the literature shows that educators have used various group sizes and various strategies in assigning students to groups and that they've used various types of tasks for groupwork. In the following section, some of the variables known to impact groupwork successfully are introduced and examined.

\subsection{Main Factors in Groupwork}

\subsubsection{Physical vs. Virtual Groupwork.}

Some researchers suggest that online communication can be as effective or more effective than face-to-face collaboration (Rezaei, 2017). However, Smith, Sorensen, Gump, Heindel, and Martinez (2011) noted that students signed up for an online course frequently believe that work in the course will be done individually; therefore, these students may resist team-based approaches to distance learning. These authors report that students in online courses were more negative about groupwork than students in face-to-face sections. In a different study, Friedman, Karniel, and Dinur (2009) did not find a significant difference in the social dynamics between online and face-to-face groups. Overall, research on the relative superiority of online versus face-to-face communication, and their roles in facilitating groupwork, is not quite conclusive (Smith, Sorensen, Gump, Heindel, \& Martinez, 2011). It could be concluded that the majority earlier studies are in favor of face-to-face groupwork in comparison with online collaboration; however, more recent studies indicate that online groupwork has its own advantages and can be quite effective (Rezaei, 2017).

\subsubsection{Anonymous vs. Non-Anonymous Groups}

Another major difference between virtual and physical discussion is the possibility of maintaining anonymity online. When group members meet face-to-face, they may be influenced by interpersonal relationships and peer pressure, which can cause group members to interact in less academic ways (Jong, Lai, Hsia \& Lin, 2013). Jong et al.'s study concluded that anonymous group discussions tend to generate better results. They argued that when students know one another reasonably well and meet face-to-face, those with a lower learning achievement may tend to rely on those with a higher learning achievement. This can in turn greatly reduce the effects of collaborative learning. Some researchers have suggested that in an anonymous group discussion, students feel safer to evaluate each other's contribution to group discussions (Wen, Tsai, \& Chang, 2006). In summary, while anonymity has a great potential for a productive group discussion, and there is strong theoretical support for it, there is no experimental research to support its effectiveness (Rezaei, 2017).

\subsubsection{Divergent vs. Convergent Discussions}

Tin (2003) categorized groupwork into convergent and divergent tasks. She explored what causes students to engage in exploratory talk and suggests that in convergent (commutative) tasks, exploratory talk may not be triggered unless the expert knowledge required to solve the problem is already at the students' potential or developmental level. She argued that in closed convergent tasks, only one outcome is expected or is true; and the participants need to converge towards a single goal. In open divergent tasks, more than one outcome is possible, and participants may often end up maintaining their own opinion, even after listening to those of the other participants. Following this Vygotskian view of interaction for learning, many educational studies have been 
conducted, investigating and identifying the features of talk desirable for learning. In summary, divergent tasks have a greater potential for a higher level of student discussion; however, convergent tasks lead to a more evenly distributed amount of work among group members (Rezaei, 2017).

\subsubsection{Large vs. Small Groups}

Although different streams of research have addressed the effects of group size, (Mueller, 2012; Wheelan, 2009) the authors have not justified their group size choices theoretically (Cummings, Kiesler, Bosaghzadeh, \& Balakrishnan, 2013). Having more members, provides more resources available to meet task demands. Larger groups sometimes perform better than smaller groups as a result of having more people. However, in larger groups, each member contributes less, on average, than in smaller groups (Liden, Wayne, Jaworski, \& Bennett, 2004). Also, larger groups have more difficulty than smaller groups reaching a common definition of the group's goals, and sustaining members' attention and cooperation, (Cummings, Kiesler, Bosaghzadeh, \& Balakrishnan, 2013).

\subsubsection{Homogeneity vs. Heterogeneity of Groups}

Homogenous ability grouping is usually used by teachers who want to form more cohesive groups and those who want to avoid slacking in groupwork. However, Nelson (2008) reports that there is a curvilinear relationship between group cohesion and group functionality. He found that groups with high levels of cohesion function just as poorly as a group with low levels of cohesion. When students of the same ability are placed together, they usually are able to work at about the same pace. However, it should be noted that in a homogenous grouping, students in lower groups receive lower quality instruction, work at a slower pace, and can detect a teacher's decreased expectations of performance and quality of instruction (Heltemes, 2009). Moreover, unlike homogenous groups in which once a student is placed in a group they may get "stuck" in the group, in heterogeneous groups it is not hard to move students (Heltemes, 2009). Teachers who let students choose their groupmates should note that these groups tend to be more homogeneous, in comparison with situations where instructors randomly assign students to groups.

\subsubsection{Peer Assessment vs. Instructor Assessment}

Peer assessment happens when the instructor allows students to evaluate each other's contributions to groupwork. This benefits students in two ways: assessing peers' work helps students to evaluate their own work; and those being assessed may accept peer assessments more readily than instructor assessments made without seeing the entire process of collaboration (Jong, Lai, Hsia \& Lin, 2013). Although an assessment of overall performance is important, as noted by Baker $(2008$, p. 183) "when the instructor focuses simply on the end result of a group project, much information is lost about specific task and relationship behaviors that affect group success," for example, the extent to which each group member took initiative, researched the issues, contributed ideas, met group deadlines, contributed to problem solving, and helped resolve group conflict. It is suggested that peer assessment not only helps students to think in a positive way about the evaluation of their work but also helps them to learn better (Rezaei, 2015). Baker (2008) compared three peer evaluation methods including two rating scales and single score methods. She concluded that all three instruments demonstrated acceptable levels of reliability and were found to be correlated with individual performance measures. When peers assess each other's work, they use their own language and communicate in their own way.

Although some instructors may question the appropriateness of allowing students to influence the grades of their peers, as reported by Baker (2008), many researchers have justified the use of peer ratings for administrative purposes because peers are frequently in the best position to observe relevant behaviors and ratings can be aggregated across peers to increase accuracy. Although peer assessment has the potential to help students learn better, it can also cause anxiety because students may fear that judging one another could lead to hard feelings (Jong, Lai, Hsia \& Lin, 2013). Students may also avoid commenting on those with greater academic performance. To tackle this problem, there are methods that allow peers to assess one another without revealing their own identities (Wen, 2006).

\section{Methodology}

In an earlier study, the authors identified 6 factors known to play a significant role in the effectiveness of groupwork in education (Rezaei, 2017). The six major factors included mode of instruction (face-to-face vs. online), type of task (convergent vs. divergent), anonymity of participants, homogeneity of students in terms of their skill level, utilization of peer assessment, and group size. For this study, a survey was developed based on these six factors and also based on the advantages and disadvantages of groupwork as reflected in the literature. 
After the approval of the Institutional Review Board (IRB) of the proposal to survey human subjects, the survey was sent to a group of 800 faculty in a Southern California university campus. Only faculty who had used groupwork in courses were asked to complete the survey. A total of 131 faculty who were using group work in their courses completed the survey. The sample included new and senior faculty from colleges of education, arts, business, health, science, and liberal arts. Among faculty who completed the survey $68 \%$ were female and $33 \%$ were male. Most participants were from the college of Health and Human services (28\%) and college of liberal arts $(24 \%)$. About $40 \%$ of participants' age was more than 50 and about $63 \%$ had more than 10 years of teaching experience.

The survey included 3 types of questions. The first part includes simple demographics. The second part included questions regarding how and how much/often they used groupwork in their courses. The third part of the survey asked faculty's opinion about what works and what does not work in groupwork assignments.

The survey was posted online and faculty were assured that their responses would be anonymous and stay confidential. A descriptive analysis was performed first, and then some correlations and analyses of variance were conducted to examine group difference. A similar survey was sent to a group of 177 volunteer students to compare faculty and students' viewpoints.

\section{Results}

The first question in the survey asked participants to stop the survey if they had not used/did not use any groupwork in their courses. Therefore, all of faculty who responded the survey had used groupwork as a part of their course assignments. However, most faculty (more than 90\%) stated that they did not allocate more than half of their grades to the groupwork. In fact, only $8 \%$ of faculty reported that more than half of their grade was based on groupwork. Most faculty assigned groupwork for either problem solving or oral presentations. About $73 \%$ of faculty never allowed collaboration on quizzes and exams, and about $65 \%$ never allowed groupwork in field work and clinical practices such as student teaching. About $40 \%$ of faculty reported that they use groupwork in order to add a multicultural perspective to projects. The types of group activities reported by the instructors in response to an open-end question included: forming groups to prepare for in-class group discussions, collaborative instructional design, group critique of art works, jigsaw activities related to readings, group essay writing, literature review and sharing, media review/critique, gamification and/or learning sprints, planning special events, peer review, and team debates.

None of the respondents believed that online group discussion was more effective than in-class group discussions. In fact, $58 \%$ of faculty stated that groupwork is more effective when it happens entirely in class, $25 \%$ believed that groupwork is more effective when it happens face to face but outside classroom, and $18 \%$ believed that group discussion is more effective when it is done partially online and partially in class.

The most effective group size, according to $80 \%$ of faculty, is groups of 3-4 students. About $9 \%$ of faculty prefer groups of 2 students and the same percentage of faculty prefer groups of 5-7 students. Only $2 \%$ of faculty believed that one should assign groupwork to the entire class as one group. Moreover, four percent of faculty reported that they believe groupwork is more effective when the instructor is not involved in the processes of students' groupwork. Fifty percent of faculty reported that they believe groupwork is more effective when the instructor is moderately involved in the processes of students' groupwork and 36 percent of faculty reported that they believe groupwork is more effective when the instructor is minimally involved in the processes of students' groupwork. Finally, $11 \%$ of faculty reported that they believe groupwork is more effective when the instructor is highly involved in the processes of students' groupwork.

A majority of faculty (75\%) reported that they believe group discussion is more effective when group members know each other to some extent and only $11 \%$ believed that group discussion is more effective when group members know each other very well. A similar percentage of faculty $(13 \%)$ believed that group discussion is more effective when group members do not know each other at all. About $58 \%$ of the instructors believed that if we let students choose their group members the groupwork will be more effective, however, $42 \%$ think it is better if the instructor assigns students to groups either randomly or based on their abilities. In response to a related question in the survey, faculty were equally divided in terms of assigning roles to group members. Fifty one percent of faculty supported the idea that for group assignments the tasks should be divided and each group member should take a different role to get the job done. The other half $(49 \%)$ believed that each group member should contribute to all tasks. However, there was a good consensus (93\%) regarding the idea that students should switch their roles for different group assignments. Only $7 \%$ of faculty supported the idea that each student should take the same role for all group assignments (for example, one student always does the written 
part and another student always presents the results). Finally, the majority of faculty (90\%) agreed that the group facilitator should change during the semester.

In this study, divergent tasks are defined as tasks that are exploratory in nature, and in which students may take different paths and come up with multiple solutions. Convergent tasks, on the other hand, are defined as tasks that require specific procedures to reach a specific goal or to find the correct solution for a problem. Faculty were asked to choose which type of task, in their opinion, is more appropriate for group work. The majority of faculty (64\%) selected divergent tasks to be more appropriate and the other $36 \%$ percent chose convergent task as the more appropriate task for groupwork.

Regarding the assessment of groupwork, $22 \%$ of faculty reported that they believe groupwork should only be evaluated by the instructor and only $4 \%$ believed that groupwork should be evaluated merely by group members. Most faculty (74\%), believed that both the instructor and students should be involved in groupwork assessment. Some instructors evaluate only the final product of a group project and some evaluate only the level and quality of discussion/ collaboration. In this study, most faculty (52\%) reported that they believe group discussion is more productive when two grades are given, one for the final product and one for individual contributions. The remainder of faculty were equally divided on this matter. $23 \%$ reported that they believed group discussion is more productive when the instructor evaluates the final product (outcome) and gives the same grade to all group members, while the other $25 \%$ reported that they believed group discussion is more productive when the instructor evaluates only the individual students' contribution to the group project rather than assessing the final outcome. No matter how the instructors evaluate students' groupwork, most faculty (72\%) believed that groupwork assignment should not be considered as a big portion students' total grade in the course. Still $28 \%$ of faculty believed groupwork is more effective when the group project assignment makes up a large portion of a student's total grade in the course.

The benefits of groupwork on course assignments were surveyed through an open-end question. Instructors' responses were reviewed and the 18 themes presented in Table 1 were extracted. The first column in the table shows the benefits of groupwork as indicated by respondent faculty.

Table 1. Benefits of groupwork assignments according to faculty

\begin{tabular}{ll}
\hline Benefits of assigning groupwork to students & Number of faculty \\
\hline Learning together / peer instruction & 38 \\
Learning teamwork / collaboration skills & 33 \\
Using multiple perspectives & 31 \\
Engaging students in learning & 18 \\
Learning communication/social skills & 13 \\
Building sense of community / creating learning networks & 8 \\
Expanded creativity / imagination & 6 \\
Doing more complex projects & 6 \\
Promoting exploratory thinking / self-directed learning & 5 \\
Improving self-confidence & 5 \\
Improving critical thinking & 4 \\
Reducing teacher workload & 4 \\
Learning time management / Sense of responsibility & 3 \\
Learning leadership skills & 3 \\
Reducing student workload & 2 \\
Helping with future learning/ scaffolding & 2 \\
Reducing competition & 2 \\
Students enjoy it & 1 \\
\hline
\end{tabular}

The drawbacks of groupwork in course assignments were surveyed through another open-end question. Instructors' responses were reviewed and the 19 themes presented in Table 2 were extracted. The first column in the table shows the drawbacks of groupwork as indicated by respondent faculty. As shown in the table, there is a great consensus on the first item in the table. 
Table 2. Drawbacks of groupwork activities according to faculty

\begin{tabular}{ll}
\hline Drawbacks of assigning groupwork to students & Number of faculty \\
\hline Slackers/ Free riding / Inequality of work done by students & 51 \\
Students not sufficiently acquainted with groupwork / time management / teamwork skills & 14 \\
Imbalance between shyness and outspoken / Strong personalities taking over & 9 \\
Bad group chemistry / interpersonal conflicts / Jealousy and resentment & 7 \\
Conflicting schedule outside class / busy students cannot contribute & 7 \\
Difference in work ethics / commitment / motivation/ abdication of responsibility & 6 \\
Students do not like it / resistance/ previous bad experience & 5 \\
Hard for the instructor to assess contributions/Most students do not provide honest assessments of their peers & 5 \\
Stressful / worried about sloppy work done by some / disappointed & 4 \\
Communication breakdown/Poor communication & 3 \\
Time consuming for instructors to administrate & 3 \\
If students come unprepared for the groupwork it drags down the whole group & 3 \\
If task is distributed not all students experience all the challenges and the work seems disconnected and they do & \\
not learn as much & 2 \\
All “A" students go together/ all C students go together & 2 \\
Distractions/Going off topic & 2 \\
Level difference & 2 \\
Unfair grading (when all get the same low grade) & 2 \\
Technical problems & 2 \\
Waist of class time particularly for student presentations/Takes time away from being exposed to more material & 2 \\
\hline
\end{tabular}

Table 3 shows how often (on a scale 1 to 5 ) faculty use the listed procedures to improve the effectiveness of groupwork. These procedures are suggested groupwork strategies by the experts in the field (Authors, 2017). The second column shows the mean (on a scale 1-5) and the third column show the standard deviation. The last column shows the percentage of faculty who reported that they always follow the procedure.

The results of t-test and analysis of variance did not show any significant differences between gender, age, and years of experience groups. However, a few significant correlations were found among variables. For example, senior faculty were mostly male. In fact, $56 \%$ of male faculty were over 50 years old while only $36 \%$ female were over 50. Senior faculty were less likely to assign research exercises to groups. Of those who said they never assign groupwork for research exercise, 54\% were over 50 years old, while among those who always assign groupwork for research, $62 \%$ were less than 50 years old. It was also found that more experienced teachers allocate less points to groupwork. Seventy percent of senior teachers reported that they never allow students to work on a quiz/exam together, while this percentage for new faculty was only $20 \%$. Another significant correlation was found between years of experience and the amount of groupwork that they assigned to students. More experienced teachers less likely allow students to work in groups for taking a quiz or an exam. Seventy two percent of senior faculty allocate less than $20 \%$ of total grade to groupwork. Finally, it was found that male faculty are more likely to let students work on a quiz/exam in groups. Indeed, sixty eight percent of female faculty reported that they never allow students to work in groups in their quiz/tests.

Table 3. Groupwork strategies suggested in the literature

\begin{tabular}{llll}
\hline Procedure & Mean & SD & Percent \\
\hline Carefully explain to students how groups will operate and how students will be graded. & 4.38 & 0.97 & $62 \%$ \\
Introduce groupwork early in the semester to set clear student expectations. & 4.17 & 1.113 & $55 \%$ \\
Establish ground rules for misconduct, cheating, and plagiarism. & 4.04 & 1.307 & $55 \%$ \\
Establish ground rules for participation and contributions. & 3.93 & 1.256 & $44 \%$ \\
Help students develop the skills they need to succeed in doing group activities. & 3.61 & 1.223 & $26 \%$ \\
Plan for each stage of groupwork. & 3.55 & 1.323 & $31 \%$ \\
Incorporate self and peer assessments for group members to evaluate your own and others' & 3.52 & 1.457 & $34 \%$ \\
contributions. & &
\end{tabular}

\subsection{Comparing Faculty and Students' View Points}

All 177 students who responded the survey stated that they have taken courses in which they have been assigned groupwork activities. In fact, about $70 \%$ of students had participated in group activities more than five times, and about 50 percent of them believed that groupwork is helpful. 
Regarding optimum group size, faculty and students almost think alike and both prefer groups of 3-4 students. However, students believed teachers should be more involved in students' group discussions. Both faculty and students believed that groupwork is more effective when it happens face to face. However, the results show that in comparison with faculty, students are more in favor of online groupwork than their instructors.

Comparing faculty and students' perspectives show that faculty are more in favor of anonymous groupwork while students prefer to work with students who they know well. Similarly, in comparison with faculty, more students believed that faculty should let students choose their group members. Like faculty, a larger percentage of students believed that divergent tasks are more appropriate for groupwork.

Similar to the data from/beliefs of faculty, $27 \%$ of students reported that they believe groupwork should only be evaluated by the instructor and only $7 \%$ believed that groupwork should be evaluated merely by group members. Most students (65\%), believed that both the instructor and students should be involved in groupwork assessment. Students and faculty also held very similar opinions about grading groupwork assignments. Most students (51\%) reported that they believe group discussion is more productive when two grades are given, one for the final product and one for individual contributions. Students' perspectives were like faculty regarding the weight of groupwork in the course grade. Seventy one percent of students believed that groupwork assignments should not be considered as a large portion of a student's total grade in the course. Still, $29 \%$ of students believed groupwork is more effective when the group project assignment makes a big portion of a student's total grade in the course.

A major difference between faculty and students was found in their opinion about the task distribution among group members. About $50 \%$ of faculty believed that each group member should contribute to all tasks in each assignment, while only $27 \%$ of students agreed with this and the other $73 \%$ preferred that the instructor assigns specific tasks to individual group members. Another significant difference between faculty and students' perspectives appeared in their answers to the open question regarding the benefits and drawbacks of groupwork. According to students, the most important benefit of groupwork is to learn about different perspectives on a specific issue, followed by the opportunity to learn and understand better. One issue faculty did not mention in their responses was the reduction in workload for students, and another was the opportunity to socialize with other students and find/make new friends. Another difference was in the variety of benefits mentioned by faculty and students. Faculty listed a lager variety of benefits (as listed above); however, students concentrated only on a few benefits.

In terms of their viewpoints about the limitations and disadvantages of groupwork assignments, students and faculty were found to have some similarities and some differences. The most important concern, according to both groups, is the fact that some students do not do their share in groupwork. There are always those who do not contribute enough and those who feel more responsible and usually end up doing most of the assigned work. However, there were other concerns that were not quite felt by faculty. For example, a concern that was more emphasized by students was scheduling conflicts and setting up meeting times. Another major concern reported mostly by students was interpersonal conflicts such as super egos, super controllers, micro mangers. Poor communication among students was mentioned by several students as a limitation of groupwork assignment. Finally, it looks like faculty have longer lists of advantages for group work activities. Perhaps this means students are not quite familiar with the theoretical foundations and the educational benefits of participation in groupwork assignments.

\section{Summary and Conclusion}

The results of this study could be quite useful for teachers who want to start groupwork assignments and those who have been using them but are not quite confident if they are assigning/using group work correctly. Descriptive statistics presented in the results section could be used as a guide for those instructors, to see the most common practices and how these practices are viewed by students. Overall, results show both faculty and students trust the importance of groupwork and have found it to be quite useful. Nevertheless, not all faculty believed in the value of groupwork assignments and even those who do believe, usually do not allocate a large portion of their course grade to groupwork.

A major finding of this research is presented in Table 1 and Table 2 where faculty have expressed their opinions about the advantages and limitations of groupwork assignment. Another finding summarized in Table 3 indicates that not all faculty follow the procedures suggested in the literature to improve the effectiveness of their groupwork assignments. One goal of this study was to see if there are any differences among faculty from different disciplines, on their views towards groupwork assignments. Surprisingly, no significant differences were found among faculty from different disciplines in terms of their groupwork teaching strategies. 
Faculty assign groupwork for various reasons. Most faculty assign groupwork because they believe students learn better when they learn together. Other faculty assign groupwork to improve students' teamwork skills, motivate and engage students, and help them to see other perspectives. While some students believe online groupwork is more beneficial than face to face, a majority of students and all of the faculty who participated in this study disagree with this. It looks like the newer generation of faculty and students are more satisfied with their online groupwork experiences.

Most of the findings of this study support that common practice by faculty matches with students' expectations and there is not a big mismatch between students' viewpoints and faculty's practice. However, some of the findings are different from what has been suggested in the literature. For example, it had been argued that if group members know each other very well, they may be influenced by interpersonal relationships and peer pressure, which can cause group members to interact in less academic ways (Jong, Lai, Hsia \& Lin, 2013). Similarly, Nelson (2008) suggested that groups with high levels of cohesion function just as poorly as a group with low levels of cohesion. Yet, the results of this study show that both faculty and students prefer that students know their group members very well. The other unexpected finding was the low percentage of students and faculty agreeing with peer evaluation as a viable assessment strategy despite strong research supporting the reliability and validity of peer evaluation.

Students' comments in this study indicate that not all tasks merit a groupwork. Some students report that while they enjoy group discussions in class to learn about other perspectives, they do not necessary enjoy working together as a team on specific projects. Students like faculty to get more involved in their groupwork, and particularly in online group discussion, they need faculty to be present. The majority of students prefer to be evaluated by the instructors rather than by their peer group. A major concern expressed by students is their difficulty in setting up meeting times outside classroom. They suggest teachers help them with the time setting. Another groupwork drawback mentioned by students is poor communication by the teacher and other students. They need their instructors to communicate with them more often and create rules and procedures for students' communications after class. They also suggest that instructors should train students in the basics of teamwork and how to work in groups effectively, and they recommend teachers to be very clear in their expectations for group projects. Finally, if the groupwork is expected to be done online, students suggest that instructors should teach some basic applications of online technologies.

These findings are important because for many instructors who want to use groupwork in their courses there is no evidenced based research to guide them. The findings help them to decide how to form groups or teams and to find out what types of tasks are more appropriate for which type of grouping. It is also important because some comments from students can really help faculty to design more effective groupwork assignments. A major limitation of this study is that this is not an experimental research to show a cause and effect relationship. However, regarding the shortage of evidence based instructional design models, this study could be considered a first step in identifying the key variables and preliminary findings on how these variables may interact in an experimental research design. In near future, the author aims to compare technology enhanced Active Learning Classrooms (classrooms designed especially for groupworks) with regular classrooms to examine differences in the level and the nature of collaboration among students.

\section{References}

Ahern, T., \& Durrington, V. (1995). Effects of Anonymity and Group Saliency on Participation and Interaction in a Computer-Mediated Small-Group Discussion. Journal of Research on Computing in Education, 28, 133-147. https://doi.org/10.1080/08886504.1995.10782156

Katz, L., \& Rezaei, A. (1999). The potentials of modern Tele-learning tools for collaborative learning. Canadian Journal of Communication, 24(3), 427-448. https://doi.org/10.22230/cjc.1999v24n3a1115

Rezaei, A. R. (2015). Frequent collaborative quiz taking and conceptual learning. Active Learning in Higher Education, 16(3), 187-196. https://doi.org/10.1177/1469787415589627

Rezaei, A. R. (2017). Features of successful group work in online and physical courses. The Journal of Effective Teaching, 17(3), 1-19.

Baker, D. (2008). Peer assessment in small groups: A comparison of methods. Journal of Management Education, 32(2), 183-209. https://doi.org/10.1177/1052562907310489

Bennett, T. (2015). Group Work for the Good; Unpacking the Research behind One Popular Classroom Strategy. American Educator, 1, 32-43 
Brown, C. A., \& McIlroy, K. (2011). Group work in healthcare students' education: what do we think we are doing? Assessment \& Evaluation in Higher Education, 36(6), 687-699. https://doi.org/10.1080/02602938.2010.483275

Cartney, P., \& Rouse, A. (2006). The emotional impact of learning in small groups: Highlighting the impact on student progression and retention. Teaching in Higher Education, 11, 79-91. https://doi.org/10.1080/13562510500400180

Chapman, H. (2005). Towards effective group-work in nurse education. Nurse Education Today, 26, 298-303. https://doi.org/10.1016/j.nedt.2005.10.010

Cummings, J. N., Kiesler, S., Bosagh Zadeh, R., \& Balakrishnan, A. D. (2013). Group Heterogeneity Increases the Risks of Large Group Size: A Longitudinal Study of Productivity in Research Groups. Psychological Science, 24(6), 880-890. https://doi.org/10.1177/0956797612463082

Fredrick, L. D., \& Hummel, J. H. (2004). Reviewing the outcomes and principles of effective instruction. In D. J. Moran \& R. W. Malott (Eds.), Evidence based educational methods (pp. 9-21). San Diego: Elsevier Academic Press. https://doi.org/10.1016/B978-012506041-7/50003-6

Friedman, D., Karniel, Y., \& Dinur, A. L. (2009). Comparing Group Discussion in Virtual and Physical Environments. Presence, 18(4), 286-293. https://doi.org/10.1162/pres.18.4.286

Groccia, J. E., \& Miller, J. E. (1996). Collegiality in the classroom: The use of peer learning assistants in cooperative learning in introductory biology. Innovative Higher Education, 21(2), 87-100. https://doi.org/10.1007/BF01243700

Heltemes, L. (2009). Social and Academic Advantages and Disadvantages of Within-class Heterogeneous and Homogeneous Ability Grouping. Retrieved from http://fisherpub.sjfc.edu/mathcs_etd_masters/93

Huang, R. (2005). Chinese International Students' Perceptions of the Problem-Based Learning experience. Journal of Hospitality, Leisure, Sport \& Tourism Education, 4(2), 36-43. https://doi.org/10.3794/johlste.42.108

Jong, B., Lai, C., Hsia, Y., Lin, T., \& Liao, Y. (2014). An exploration of the potential education value of Facebook. Computers in Human Behavior, 32, 201-211. https://doi.org/10.1016/j.chb.2013.12.007

Lammers, W. J., \& Murphy, J. J. (2002). A profile of teaching techniques in the university classroom: A descriptive profile of a US public university. Active Learning in Higher Education, 3, 54-67. https://doi.org/10.1177/1469787402003001005

Lave, J., \& Wenger, E. (1991). Situated learning: Legitimate peripheral participation. Cambridge, UK: Cambridge University Press. https://doi.org/10.1017/CBO9780511815355

Mueller, J. S. (2012). Why individuals in larger teams perform worse. Organizational Behavior and Human Decision Processes, 117, 111-124. https://doi.org/10.1016/j.obhdp.2011.08.004

Qamar, M. R., Ahmad, A., \& Niaz, K. (2015). Learning through small group discussion versus didactic lectures. Pakistan Armed Forces Medical Journal, 65(3), 386-390.

Smith, G. G., Sorensen, C., Gump, A., Heindel, A. J., Caris, M., \& Martinez, C. D. (2011). Overcoming student resistance to group work: Online versus face-to-face. The Internet and Higher Education, 14, 121-128. https://doi.org/10.1016/j.iheduc.2010.09.005

Tin, T. B. (2003). Does talking with peers help learning? The role of expertise and talk in convergent group discussion tasks. Journal of English for Academic Purposes, 2, 53-66. https://doi.org/10.1016/S1475-1585(02)00033-4

Vygotsky, L. (1986). Mind in society. Cambridge, MA: Harvard University Press.

Wen, M. L., Tsai, C. C., \& Chang, C. Y. (2006). Attitudes towards peer assessment: A comparison of the perspectives of pre-service and in-service teachers. Innovative Education Teaching International, 43, 83-92. https://doi.org/10.1080/14703290500467640

Wheelan, S. A. (2009). Group size, group development, and group productivity. Small Group Research, 40, 247-262. https://doi.org/10.1177/1046496408328703 


\section{Copyrights}

Copyright for this article is retained by the author, with first publication rights granted to the journal.

This is an open-access article distributed under the terms and conditions of the Creative Commons Attribution license (http://creativecommons.org/licenses/by/4.0/). 